American Journal of Applied Sciences 5 (12): 1720-1729, 2008

ISSN 1546-9239

(C) 2008 Science Publications

\title{
A Decision Support Approach for the Sustainable Transfer of Energy Technologies under the Kyoto Protocol
}

\author{
Charikleia Karakosta, Haris Doukas and John Psarras \\ National Technical University of Athens, School of Electrical and Computer Engineering, \\ Energy Policy Unit of the Management and Decision Support Systems Laboratory (EPU-NTUA), \\ 9, Iroon Polytechniou str., 157 80, Athens, Greece
}

\begin{abstract}
Theoretically, the Clean Development Mechanism (CDM) was introduced in the Kyoto Protocol at COP-3 in December 1997 and has officially been operational since the year 2000, in order to assist the technology transfer of sustainable energy technologies from developed to developing countries so as to support the sustainable development of the host countries. Under the CDM, sustainable development is considered a country context-specific aspect which differs across countries. Actual CDM practice has shown that projects are largely initiated by the demand for relatively lowcost certified emission reductions, leading to a series of ad-hoc projects, rather than serving the overall host countries' sustainable development needs and priorities. Indeed, it remains to be seen how important the mechanism can be in terms of stimulating the sustainable transfer of energy technologies to developing countries. This study, a part of which is based on research conducted within the FP6 ENTTRANS project, aims to present a collective and transparent approach towards the sustainable technology transfer through the CDM, based on the active involvement of the related stakeholders in five developing countries, namely China, Chile, Israel, Kenya and Thailand. Specifically, the adopted approach uses an existing Multi Criteria Decision Making (MCDM) method, giving emphasis on the formulation of the process so as to be relatively straightforward to incorporate direct stakeholders' preferences. The approach aims to facilitate decision makers to put on the map the most suitable sustainable energy technologies to transfer to these specific developing countries and support these host countries' DNAs-Designated National Authorities in building the capacity to explore CDM projects contribution to the related sustainable development needs and priorities.
\end{abstract}

Key words: Technology transfer, multi criteria analysis, sustainable development, clean development mechanism

\section{INTRODUCTION}

The Kyoto Protocol contains market mechanisms that enable industrialized countries to invest in greenhouse gas emission (GHG) reduction projects on the territory of other countries, either developing, or industrialised, such as the Clean Development Mechanism (CDM) and the Joint Implementation (JI) ${ }^{[1]}$.

Given the double objective of the CDM-GHG emission reduction and enhancing sustainable development-a typical CDM project would bring together industrialised countries' demand of GHG emission reduction credits and developing countries' demand for sustainable (energy) technologies and other means to achieve development goals. Ideally, a CDM project would therefore be based on a clear assessment of the GHG emission reduction potential and a clear assessment of the technology needs and development priorities in the host country. Actual CDM practice, however, has shown that such projects are largely initiated by the demand for relatively low-cost Certified Emission Reductions (CERs), leading to a series of adhoc projects, rather than serving the overall policy objectives of the host countries.

This has among others resulted in a situation in which the distribution of projects across developing host countries is rather skewed towards a small group of countries that have taken between 80 and $90 \%$ of the CDM market as suppliers of projects and (expected) emission reduction credits. The latter is shown, in

Corresponding Author: Charikleia Karakosta, National Technical University of Athens, School of Electrical and Computer Engineering, Energy Policy Unit of the Management and Decision Support Systems Laboratory (EPUNTUA), 9, Iroon Polytechniou str., 157 80, Athens, Greece Tel: +30-210-7722083/2084 Fax: +30-210-7723550 


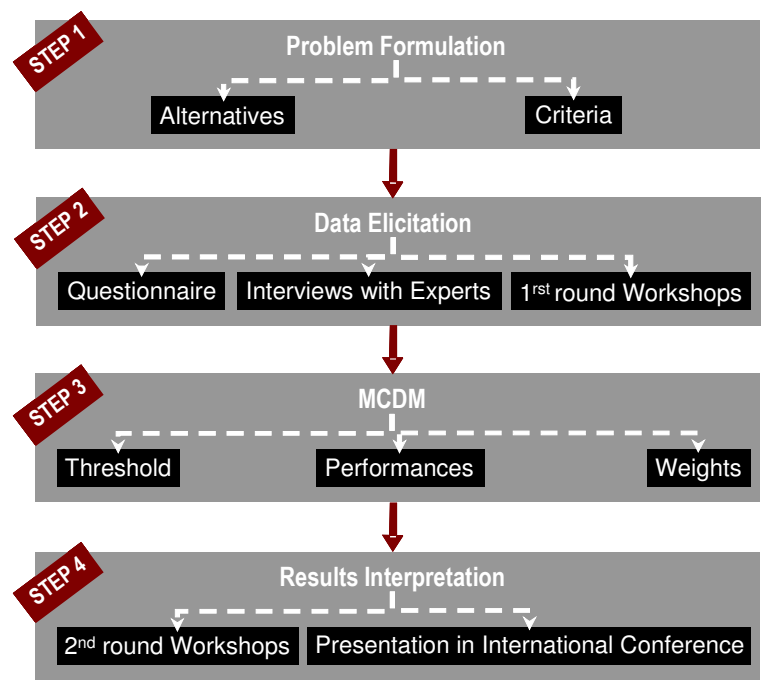

Fig. 1: Methodological approach

Fig. 1, which shows the amount of CERs issued based on ongoing CDM projects. As it can be seen India, China, South Korea and Brazil have thus far supplied 90\% of issued CERs, (actually realised GHG emission reductions which have been verified and issued by the CDM Executive Board). In terms of expected credits (emission reductions expected from projects planned or ongoing), China, India, Brazil, South Korea and Mexico (in that order) presently have a share of $84 \%$ of the pipeline; in terms of proposed projects, this percentage is $79 \%{ }^{[2,3]}$. Consequently, although the pipeline of CDM projects contains a large number of projects, there is no equal distribution of projects across the world.

Based on domestic, business as usual priorities and needs, countries may choose an energy technology profile that may not be the best in terms of delivering long term sustainability and GHG reductions, since sustainable technologies are not included or even considered. The CDM could help raise the energy profile of a country towards the first-best level, provided that the host country has in place a welldeveloped strategy for sustainable energy technology implementation in combination with the CDM. However, it remains to be seen how important the mechanism can be in terms of stimulating the transfer of sustainable energy technologies to developing countries. To move towards the sustainable technology transfer, evident is the need to turn the selection of the technology implemented under the CDM towards the host country specific needs and priorities.

Indeed, the selection of the most suitable sustainable energy technology for implementation under the CDM is a problem that decision makers often face and in which multiple conflicting goals or criteria have to be considered ${ }^{[4]}$. Multicriteria analysis forms a very useful tool in order to take into account simultaneously all the basic aspects of the problem during the formulation of priorities for the implementation of various technology alternatives and represents a sound methodology applied internationally during the last decade in several problems of environmental and energy planning ${ }^{[5,6,7,8,9]}$.

In the above framework, the study aims to present a collective and transparent approach, based on the active involvement of the related stakeholders, to support the sustainable technology transfer through the CDM, taking also into consideration the overall medium to long-term energy and environmental strategy of the host country. Specifically, the adopted approach uses an existing Multi Criteria Decision Making (MCDM) method, namely the ELECTRE Tri Method; which has the objective to categorize the available sustainable energy technology alternatives for electricity generation according to their contribution to sustainable development, by examining their economic, environmental and social benefits. The current approach lays emphasis on the formulation of the process so as to be relatively straightforward to incorporate direct experts' preferences as well as trying to deal with the needs of flexibility and validity. The presented approach could facilitate decision makers to put on the map the most suitable sustainable energy technologies to transfer in five developing countries, China, Chile, Israel, Kenya and Thailand and support these host countries' DNAs-Designated National Authorities in building the capacity to explore CDM projects contribution to the related sustainable development needs and priorities.

Apart from the introduction, the study is structured along three sections. The second section is devoted to the presentation of the materials and methods, which consists of the analysis of the proposed in-country participatory process for the elicitation of structured information and the customization of the MCDM method within the specific problem characteristics. The results from the application are presented in the third section, while the last section is the discussion of the main outcomes, summarizing the main points that have arisen in this study.

\section{MATERIALS AND METHODS}

Adopted approach: The proposed approach is build, in a large extent on the emerging insights of the European Commission (EC) FP6 ENTTRANS, the potential of 
Am. J. Applied Sci., 5 (12): 1720-1729, 2008

transferring and implementing sustainable energy technologies through the Clean Development Mechanism of the Kyoto Protocol project, which aims at supporting the host country DNA in building the capacity to explore which CDM projects would contribute to the countries' sustainable development needs and priorities. The case study countries of the specific project are Chile (CL), China (CN), Israel (IL), Kenya (KE) and Thailand (TH). The methodological approach analysed in this subsection, which is based on the information and data acquired through international organisations' publications and the kind contribution of local experts, is structured along three (4) steps as shown graphically in Fig. 1.

In advance, for the first step of the approach, a desk study analysis was elaborated for the identification of the sustainable energy technologies for electricity generation to be examined in the context of this study. An overview of the current status of the already known technologies in the developing countries was conducted. In particular, the study included a literature review of the technology options for CDM projects development and analytical information collection from international sources and publications on the present penetration of the examined technologies in energy systems in various regions, an estimation of growing potential of the technologies with a view to $R$ and $D$, the availability of space and resources and the social acceptability.

The sustainable energy technologies finally selected for electricity generation are listed below Table 1:

For the assessment of these technologies a number of parameters had to be incorporated in the analysis, such as cost aspects, social impacts, GHG reductions as well as environmental impacts, based on the specific characteristics, development needs and perspectives of each country. The research focuses on the provision of a small but clearly understood set of evaluation criteria, which can form a sound basis for the comparison of the examined energy options in terms of their contribution to sustainable development through the CDM. Concisely, the six criteria incorporating the benefits in the economic, environmental and social dimension are presented in Table 2.

The specific question addressed in this study is the categorization of the examined CDM energy technologies according to their contribution to sustainable development. The predefined categories for the classification of the various measures were limited to three, $\mathrm{C} 1, \mathrm{C} 2$ and $\mathrm{C} 3$, where $\mathrm{C} 1$ stands for the high priority category, C2 stands for the low priority category and C3 stands for the not recommended category.
Table 1: The Alternatives

T1: Clean coal

T2: Steam boiler upgrading

T3: Coal-to-gas

T4: Oil steam improvement

T5: Coal steam improvement

T6: Methane combustion

T7: Hydro (dams)

T8: Geothermal

T9: Wind

T10: Solar (pv)

T11: Mini/micro hydro (rivers)

T12: Biomass (forest/agriculture) boiler

T13: Biogas for generator

T14: Mini/micro decentralized

T15: Solar towers

T16: Coal Mine Methane (CMM) for generator

Table 2: The Criteria

\begin{tabular}{|c|c|}
\hline Criterion & Description of criterion \\
\hline $\begin{array}{l}\text { K1: Accordance } \\
\text { with strategic/ } \\
\text { developmental } \\
\text { planning }\end{array}$ & $\begin{array}{l}\text { Reflects the accordance of particular technologies } \\
\text { with the strategic and developmental planning of } \\
\text { each country. The higher the accordance with } \\
\text { strategic planning in a specific country the higher } \\
\text { the performance of a specific technology in } \\
\text { this criterion. }\end{array}$ \\
\hline $\begin{array}{l}\text { K2: Local and } \\
\text { regional } \\
\text { economic } \\
\text { development }\end{array}$ & $\begin{array}{l}\text { Represents the repercussion of a particular } \\
\text { technology in the local and regional development. } \\
\text { It does not include the impact on the employment, } \\
\text { while it incorporates the extent to which the local } \\
\text { enterprises bloom due to the investments in the } \\
\text { region. The higher the growth achieved the higher } \\
\text { the performance. }\end{array}$ \\
\hline $\begin{array}{l}\text { K3: } \mathrm{CO}_{2} \\
\text { emissions } \\
\text { reduction }\end{array}$ & $\begin{array}{l}\text { Represents the estimated reduction of } \mathrm{CO}_{2} \\
\text { emissions that will be achieved via the } \\
\text { implementation of each alternative. The choices } \\
\text { with the higher possible reduction are evaluated } \\
\text { higher than the options with lower } \mathrm{CO}_{2} \\
\text { reduction potential. }\end{array}$ \\
\hline $\begin{array}{l}\text { K4: Minimization } \\
\text { of the negative } \\
\text { effects on the } \\
\text { natural } \\
\text { environment at } \\
\text { national-regional } \\
\text { level }\end{array}$ & $\begin{array}{l}\text { Reflects the level of repercussion of the } \\
\text { alternative in the natural environment, } \\
\text { incorporating the noise levels, esthetic } \\
\text { interruptions, pressure on land resources and } \\
\text { excessive land use. Options with the least } \\
\text { possible impact are ranked higher. }\end{array}$ \\
\hline $\begin{array}{l}\text { K5: Contribution } \\
\text { to the } \\
\text { employment }\end{array}$ & $\begin{array}{l}\text { Reflects the impact of the examined option in } \\
\text { the social dimension as far as the employment } \\
\text { rates are concerned. The higher the contribution } \\
\text { to net employment generation, the higher the } \\
\text { performance in this criterion. }\end{array}$ \\
\hline $\begin{array}{l}\text { K6: Contribution } \\
\text { to the energy } \\
\text { sufficiency } \\
\text { (independence) }\end{array}$ & $\begin{array}{l}\text { This criterion depicts the extent to which each } \\
\text { examined option contributes to the country's } \\
\text { energy independence, by substituting certain } \\
\text { amounts of the consumed primary energy. }\end{array}$ \\
\hline
\end{tabular}

An appropriate questionnaire was prepared in terms of the second step, for use in bilateral interviews with energy sector, research and policy stakeholders in each country. The developed questionnaires were presented in a 1 st round of data triggering workshops in the case study countries (Chile-November 2006, ChinaDecember 2006, Israel-Tel-Aviv January 2007, Kenya- 
September 2006, Thailand-October, 2006), where the questionnaires were distributed to all relevant stakeholders and all useful information and instructions related to the questionnaires completion were provided to them.

Stakeholders have been asked to rank technologies according to the economic, environmental and social benefits that could be delivered in their country towards sustainable development. Each question could be answered by assigning values from 1 (low priority, suitability) to 5 (very high priority, suitability). In this context, stakeholders provided with appropriate data, information, input and feedback through these interviews and the examined technologies' performances to the criteria were elaborated ${ }^{[10]}$. The stakeholders have been selected from governmental departments with responsibility for energy, environment and development issues, representative national and international companies or bodies in other GHG intensive sectors (e.g., energy intensive industry), financial institutions involved in the manufacture, import and sale of environmentally sound technologies, international organizations and donors, local organizations as well as NGOs involved in the promotion of environmental and social objectives. Bilateral interviews were conducted with the abovementioned energy actors so as to assist the completion of the questionnaires and accelerated the procedures. Indeed, these interviews were a significant source of eliciting all the appropriate structured data for modelling the MCDM.

Following the second step's dispatch, collection and evaluation of the questionnaires addressed to energy actors of the case study countries, data and information on the alternatives' performances in the specific criteria as well as the related thresholds and weights were provided in the third step.

All input acquired from key actors and stakeholders were entered in the proposed MCDM approach, as described in detail in the following subsection and initial outcomes were received for each country. Following, 2nd round of regional participatory stakeholder assessment workshops were organised in each case study country (Chile-June 2007, China-July 2007, Israel-Tel-Aviv October 2007, Kenya-Nairobi October 2007, Thailand-Bangkok July 2007) in terms of the $4^{\text {th }}$ step. In these workshops data gaps were filled as well as information crossover has taken place. Moreover, the workshops atmosphere was appropriate for commenting, interpreting the structure of the data, discussing the outputs and the main points that had emerged so far. In addition, the outcomes obtained from the proposed approach were presented in an
International Conference in order to be judged by the relevant stakeholders, which participated. Therefore, qualitative interpretation of the initial and the final results was provided by relevant stakeholders.

MCDM method's customization: The MCDM approach was selected due to the fact that these methods provide the flexibility and capacity to support the views of many decision makers or stakeholders ${ }^{[11]}$ and support the evaluation of the most suitable sustainable energy technologies to transfer and implement in a developing country through the CDM. In particular, these methods have been applied to a wide range of electricity sector issues, such as for environmental assessment ${ }^{[12]}$, for the prioritisation of environmental projects ${ }^{[13]}$ and for electricity planning ${ }^{[14]}$.

In the scientific literature (and in reality) there are many applications of MCDM method in different decision making problems ${ }^{[15,16,17]}$. Multi-criteria analysis has been used in order to select preferable options among multi-attribute discrete alternatives, which is the case for this particular problem. Outranking methods have known a rapid development during the last decade and have been considered as suitable for such problems, with ELECTRE and PROMETHEE being two of the most known and widely applied outranking methods ${ }^{[18,19]}$.

Out of the various outranking multiple criteria decision-aid methods available (e.g., ELECTRE, PROMETHEE, PRAGMA/MACCAP, etc.), the ELECTRE Tri method was selected. It is the most recent out of the methods of the ELECTRE family-was developed in 1992-and has been applied in problems related to environmental planning, business risk, etc $^{[20,21,22,23]}$.

ELECTRE Tri is characterised by its ability to assign alternatives to pre-defined categories. Furthermore, ELECTRE Tri can better approximate the attitude of decision-makers, which is usually characterised by a gradual transition from the indifference to the preference state ${ }^{[24]}$.

The method was considered appropriate for application in this specific problem due to the following reasons: A particular characteristic of the ELECTRE Tri method is that it provides the possibility of assigning potential actions into pre-defined categories and thus it is suitable for exploring which alternative sustainable energy technologies can be considered as of high, low priority and not recommended options. The latter two categories do not necessarily comprise less desired technologies; they can include technologies that require better (market, technology, social etc.) 
conditions for their implementation through the CDM than the existing ones.

The ELECTRE Tri method is basically a two stage process $^{[25,26]}$. In the first stage, the outranking hypothesis action a is at least as good as the reference action of a pre-defined category is tested. In the second stage, the outranking relations established in the previous step are exploited in order to classify potential actions in the various pre-defined categories (the number of categories is defined by the user). This classification is performed through two processes, the optimistic classification, where the action is classified to the highest possible category and the pessimistic classification, where the action is classified to the lowest possible category.

More specifically, the assignment of an alternative a in Electre Tri results from the comparison of a with the profiles defining the limits of the categories. Let $\mathrm{F}$ denote the set of the indices of the criteria $g_{1}, g_{2}, \ldots, g_{m}$ $(F=\{1,2, \ldots, m\})$ and $B$ the set of indices of the profiles defining $p+1$ categories $(B=\{1,2, \ldots, p\}), b_{h}$ being the upper limit of category $\mathrm{C}_{\mathrm{h}}$ and the lower limit of category $\mathrm{C}_{\mathrm{h}+1}, \mathrm{~h}=1,2, \ldots, \mathrm{p}$. ELECTRE Tri assigns alternatives to categories following two consecutive steps $^{[27]}$ :

- Construction of an outranking relation $\mathrm{S}$ that characterises how alternatives compare to the limits of categories

- Exploitation (through assignment procedures) of the relation $\mathrm{S}$ in order to assign each alternative to a specific category

In this framework, ELECTRE Tri builds an outranking relation $S$, i.e., validates or invalidates the assertion $\mathrm{aSb}_{\mathrm{h}}$, whose meaning is a is at least as good as $b_{h}$. The assertion $b_{h} S a$, whose meaning is $b_{h}$ is at least as good as a is also validated or invalidated in the same way.

ELECTRE Tri requires from the user to ${ }^{[28]}$ :

- Define the alternatives, the criteria as well as the pre-defined categories for their classification

- Determine the values for the performances of the alternatives to the criteria and the indifference, strict preference and veto thresholds

In this specific problem formulation, the alternatives constitute of the examined technologies, as illustrated in the Table 1 and the criteria incorporate the technologies' contribution to sustainability, as illustrated in the Table 2. Regarding thresholds, the cutting level $\lambda$ is set to 0.76 . It's not very high in order to avoid the differences between the two classifications (optimistic and pessimistic). The indifference threshold is set to 0 and the preference threshold to 2 for all the criteria in both profiles. The high preference threshold is selected in order to eliminate the uncertainties in the exact scores of each criterion. It should be noted that the selection of indifference threshold values is based on the proposed approach. Experts, frequently, are assigning totally different values in the alternatives as regards their performance in specific criteria. Due to this uncertainty the preference threshold is set high, to eliminate the possibility of having wrong strict preference among the alternative technologies. The performances were assigned by the stakeholders in an ordered scale from 1 (low priority, suitability) to 5 (very high priority, suitability), as already discussed in the previous subsection. Based on the performances assigned, the profiles defining the upper and the lower limit of the categories were also elaborated as the average of the performances of the technology alternatives in each criterion for the upper limit and the value of the upper limit minus one as regards the lower limit, as also applied by Georgopoulou et al. $(2003)^{[24]}$.

Based on the abovementioned process the related inputs (performances and weights for each country) to the Electre Tri method were defined, as illustrated in the following Table 3.

It is important to mention some comments that were revealed in each case study country in the context of the elicitation of the stakeholders' preference:

- In all case study countries a lack of knowledge among most of the interviewees regarding the less known energy technologies was observed

- Completeness and representative result of the Chinese case is really difficult to be accomplished, due to the large area and variety of China

- In Kenya, stakeholders stated that importing technologies requires a very complex custom procedure (over 30 forms to fill in) and that implementing some technology alternatives may conflict with the culture in the country

- The stakeholders workshop in Thailand resulted in the fact that clean electricity production is on the one hand subsidised with a feed-in tariff whereas, on the other hand, an import tax on the technology must be paid when it is foreign. This is an example that in this case and in this implementation chain, two governmental policies are contradictory 
Am. J. Applied Sci., 5 (12): 1720-1729, 2008

Table 3: Inputs

\begin{tabular}{|c|c|c|c|c|c|c|c|c|c|c|c|c|c|c|c|c|c|}
\hline & \multirow[b]{2}{*}{ Weights } & \multicolumn{16}{|c|}{ Technology Alternatives } \\
\hline & & $\mathrm{T} 1$ & $\mathrm{~T} 2$ & $\mathrm{~T} 3$ & $\mathrm{~T} 4$ & T5 & T6 & $\mathrm{T} 7$ & $\mathrm{~T} 8$ & T9 & $\mathrm{T} 10$ & T11 & T12 & T13 & T14 & $\mathrm{T} 15$ & $\mathrm{~T} 16$ \\
\hline \multicolumn{18}{|c|}{ Criterion K1 } \\
\hline $\mathrm{CL}$ & 4 & 3 & 3 & 3 & 3 & 2 & 4 & 3 & 4 & 4 & 3 & 4 & 4 & 3 & 4 & 2 & 3 \\
\hline $\mathrm{CN}$ & 4 & 4 & 4 & 3 & 3 & 4 & 4 & 4 & 2 & 4 & 4 & 4 & 3 & 3 & 2 & 2 & 3 \\
\hline IL & 4 & 4 & 3 & 2 & 2 & 3 & 2 & 1 & 4 & 4 & 4 & 3 & 4 & 2 & 4 & 2 & 5 \\
\hline $\mathrm{KE}$ & 4 & 2 & 2 & 0 & 1 & 2 & 2 & 3 & 4 & 3 & 4 & 4 & 3 & 3 & 2 & 2 & 0 \\
\hline $\mathrm{TH}$ & 4 & 4 & 5 & 3 & 3 & 3 & 4 & 3 & 3 & 2 & 3 & 3 & 5 & 5 & 3 & 3 & 2 \\
\hline \multicolumn{18}{|c|}{ Criterion K2 } \\
\hline CL & 3 & 4 & 5 & 3 & 3 & 4 & 5 & 4 & 5 & 4 & 5 & 5 & 5 & 4 & 4 & 2 & 1 \\
\hline $\mathrm{CN}$ & 3 & 4 & 3 & 3 & 4 & 5 & 3 & 3 & 3 & 4 & 4 & 4 & 3 & 4 & 3 & 2 & 4 \\
\hline IL & 3 & 2 & 2 & 3 & 2 & 2 & 2 & 2 & 1 & 4 & 4 & 3 & 4 & 2 & 4 & 2 & 5 \\
\hline $\mathrm{KE}$ & 4 & 2 & 2 & 0 & 1 & 1 & 2 & 4 & 3 & 3 & 4 & 3 & 3 & 5 & 3 & 2 & 0 \\
\hline $\mathrm{TH}$ & 3 & 4 & 5 & 3 & 3 & 4 & 2 & 2 & 2 & 3 & 3 & 2 & 4 & 5 & 4 & 2 & 2 \\
\hline \multicolumn{18}{|c|}{ Criterion K3 } \\
\hline CL & 4 & 4 & 3 & 4 & 3 & 3 & 4 & 2 & 2 & 5 & 3 & 4 & 5 & 5 & 4 & 4 & 4 \\
\hline $\mathrm{CN}$ & 4 & 4 & 3 & 4 & 3 & 3 & 4 & 2 & 2 & 5 & 3 & 4 & 5 & 5 & 4 & 4 & 4 \\
\hline IL & 4 & 4 & 3 & 4 & 3 & 3 & 4 & 2 & 2 & 5 & 3 & 4 & 5 & 5 & 4 & 4 & 4 \\
\hline $\mathrm{KE}$ & 4 & 4 & 3 & 4 & 3 & 3 & 4 & 2 & 2 & 5 & 3 & 4 & 5 & 5 & 4 & 4 & 4 \\
\hline $\mathrm{TH}$ & 4 & 4 & 3 & 4 & 3 & 3 & 4 & 2 & 2 & 5 & 3 & 4 & 5 & 5 & 4 & 4 & 4 \\
\hline \multicolumn{18}{|c|}{ Criterion K4 } \\
\hline CL & 5 & 3 & 5 & 3 & 3 & 4 & 4 & 3 & 4 & 5 & 5 & 4 & 5 & 4 & 4 & 2 & 1 \\
\hline $\mathrm{CN}$ & 5 & 4 & 3 & 3 & 5 & 5 & 4 & 3 & 3 & 4 & 4 & 3 & 3 & 4 & 3 & 2 & 4 \\
\hline IL & 5 & 2 & 4 & 5 & 2 & 2 & 1 & 1 & 2 & 2 & 3 & 4 & 3 & 2 & 3 & 2 & 5 \\
\hline $\mathrm{KE}$ & 5 & 2 & 2 & 0 & 1 & 1 & 2 & 4 & 3 & 3 & 4 & 3 & 3 & 5 & 3 & 2 & 0 \\
\hline $\mathrm{TH}$ & 5 & 3 & 5 & 3 & 3 & 4 & 2 & 2 & 4 & 3 & 2 & 2 & 4 & 3 & 4 & 2 & 2 \\
\hline \multicolumn{18}{|c|}{ Criterion K5 } \\
\hline CL & 3 & 1 & 3 & 2 & 1 & 1 & 2 & 2 & 1 & 4 & 5 & 3 & 4 & 3 & 2 & 2 & 5 \\
\hline $\mathrm{CN}$ & 3 & 1 & 3 & 2 & 1 & 1 & 2 & 2 & 1 & 4 & 5 & 3 & 4 & 3 & 2 & 2 & 5 \\
\hline IL & 3 & 1 & 3 & 2 & 1 & 1 & 2 & 2 & 1 & 4 & 5 & 3 & 4 & 3 & 2 & 2 & 5 \\
\hline $\mathrm{KE}$ & 4 & 1 & 3 & 2 & 1 & 1 & 2 & 2 & 1 & 4 & 5 & 3 & 4 & 3 & 2 & 2 & 5 \\
\hline $\mathrm{TH}$ & 3 & 1 & 3 & 2 & 1 & 1 & 2 & 2 & 1 & 4 & 5 & 3 & 4 & 3 & 2 & 2 & 5 \\
\hline \multicolumn{18}{|c|}{ Criterion K6 } \\
\hline CL & 5 & 3 & 4 & 2 & 3 & 3 & 2 & 5 & 2 & 3 & 2 & 4 & 2 & 2 & 2 & 2 & 2 \\
\hline $\mathrm{CN}$ & 4 & 5 & 5 & 2 & 4 & 5 & 2 & 5 & 1 & 3 & 2 & 4 & 2 & 2 & 2 & 2 & 5 \\
\hline IL & 4 & 3 & 2 & 4 & 2 & 3 & 2 & 2 & 2 & 3 & 3 & 3 & 2 & 2 & 3 & 2 & 5 \\
\hline $\mathrm{KE}$ & 4 & 2 & 2 & 0 & 1 & 1 & 2 & 4 & 5 & 3 & 2 & 3 & 2 & 2 & 2 & 2 & 0 \\
\hline $\mathrm{TH}$ & 4 & 3 & 4 & 3 & 3 & 3 & 2 & 3 & 2 & 3 & 2 & 2 & 4 & 2 & 2 & 2 & 2 \\
\hline
\end{tabular}

\section{RESULTS AND DISCUSSION}

Based on the collected data from the stakeholders, the outcomes from the MCDM application per country, as resulted from the ELECTRE Tri method, are illustrated in the following Table 4.

China: Clean coal and coal steam improvement are high priority technology alternatives. These technologies are in line with the energy strategies of China and could assist the country in $\mathrm{CO}_{2}$ emissions abatement from coal electricity generation. Indeed, China has great reserves of coal and is planning to increase the use of coal for electricity generation ${ }^{[29]}$. In addition, methane combustion is considered as an appropriate technology for the specific country, with significant sustainability benefits and the ability of reducing the level of methane concentration in atmosphere, which is a goal of the Chinese government.
On the other hand, there is a limited interest in the use of natural gas technologies ${ }^{[27]}$. There is a constant uncertainty about the natural gas imports from Russia, in combination with the continuously increasing cost. The coal to gas technology results as a low priority option, which is reasonable due to the current circumstances. Moreover, the technology biomass boiler in China seems not to be the first priority mainly as regards the development goals of the country despite its large potentials. Finally, the geothermal technology is a not recommended alternative due to the limited domestic potential of China.

Chile: Most of Chile's coal consumption is for electricity generation. Hydropower is a proven technology in the country and supplies the largest share of Chile's electricity demand. In addition, the reach of rivers land of Chile makes it the ideal site for the implementation of the technology alternative 
Am. J. Applied Sci., 5 (12): 1720-1729, 2008

Table 4: Outcomes

\begin{tabular}{|c|c|c|}
\hline High Priority & Low priority & Not recommended \\
\hline \multicolumn{3}{|l|}{ Outcomes in China } \\
\hline Clean coal & Coal-to-gas & Geothermal \\
\hline Coal steam improvement & Biomass (forest/agriculture) boiler & Solar towers \\
\hline Methane combustion & Oil steam improvement & \\
\hline Wind & Hydro (dams) & \\
\hline Solar (pv) & Steam boiler upgrading & \\
\hline Mini/micro hydro (rivers) & Mini/micro decentralized & \\
\hline \multicolumn{3}{|l|}{ Biogas for generator } \\
\hline \multicolumn{3}{|l|}{ CMM for generator } \\
\hline \multicolumn{3}{|l|}{ Outcomes in Chile } \\
\hline Mini/micro hydro (rivers) & Clean coal & Solar towers \\
\hline Wind & Geothermal & $\mathrm{CMM}$ for generator \\
\hline Methane combustion & Hydro (dams) & \\
\hline Steam boiler upgrading & Coal-to-gas & \\
\hline Biomass (forest/agriculture) boiler & Oil steam improvement & \\
\hline \multirow[t]{4}{*}{ Mini/micro decentralized } & Coal steam improvement & \\
\hline & Solar (pv) & \\
\hline & Biogas for generator & \\
\hline & Clean coal & \\
\hline \multicolumn{3}{|l|}{ Outcomes in Israel } \\
\hline Coal-to-gas & Clean coal & Oil steam improvement \\
\hline Solar (pv) & Steam boiler upgrading & Geothermal \\
\hline $\mathrm{CMM}$ for generator & Coal steam improvement & Hydro (dams) \\
\hline Wind & Biogas for generator & Methane combustion \\
\hline Mini/micro hydro (rivers) & Solar towers & \\
\hline \multicolumn{3}{|l|}{ Biomass (forest/agriculture) boiler } \\
\hline \multicolumn{3}{|l|}{ Mini/micro decentralized } \\
\hline \multicolumn{3}{|l|}{ Outcomes in Kenya } \\
\hline Hydro (dams) & Geothermal & Coal-to-gas \\
\hline Mini/micro hydro (rivers) & Clean coal & Oil steam improvement \\
\hline Biomass (forest/agriculture) boiler & Steam boiler upgrading & Coal steam improvement \\
\hline Biogas for generator & Methane combustion & CMM for generator \\
\hline Solar (pv) & Solar towers & \\
\hline \multicolumn{3}{|l|}{ Wind } \\
\hline \multicolumn{3}{|l|}{ Mini/micro decentralized } \\
\hline \multicolumn{3}{|l|}{ Outcomes in Thailand } \\
\hline Steam boiler upgrading & Solar (pv) & Hydro (dams) \\
\hline Biogas for generator & Coal-to-gas & CMM for generator \\
\hline Biomass (forest/agriculture) boiler & Oil steam improvement & \\
\hline Clean coal & Methane combustion & \\
\hline Coal steam improvement & Geothermal & \\
\hline \multirow[t]{3}{*}{ Mini/micro decentralized } & Wind & \\
\hline & Mini/micro hydro (rivers) & \\
\hline & Solar towers & \\
\hline
\end{tabular}

mini/micro hydro (rivers) and the technology seems to have very positive effects on the natural environment in local-regional level. However, the contribution of conventional thermal sources has grown rapidly since the start of natural gas imports from Argentina in the late 1990s. Chile imports great amounts of natural gas from Argentina, but lately these imports are being restricted $^{[29]}$. That led Chile in trying to find alternative sources such us importing LNG and coal. Consequently, the technology steam boiler upgrading, which is categorized as high priority is a realistic result. The country obtains a high wind potential due to its geographical location and the long seaside and plans the development of new wind power stations. Therefore, it seems reasonable that wind energy technology is considered as a high priority technology. There has been heightened interest recently in Chile's geothermal potential as the technology appears to be able to contribute significantly to the local and regional economic development. However, the geothermal technology s categorised as a low priority alternative due to the fact that it does not contribute to the country's energy independence.

Israel: Electricity in Israel is generated from conventional thermal plants, which use primarily coal and secondary natural gas and oil. There is a strong willingness to switch from coal to gas $^{[29]}$. Israel is 
introducing natural gas into its fuel mix, especially for electricity generation, for energy security, economic and environmental reasons. It is anticipated that natural gas will supply $25 \%$ of the national energy by 2025 . This can explain why the switching from coal to gas powered facilities transformation is a very promising technology alternative in Israel. Israel has offshore natural gas reserves and switching to this type of energy can offer many opportunities for $\mathrm{CO}_{2}$ emissions reduction. Solar (PV) technology seems also very promising and is categorised as a high priority one due to the domestic potential, the geographical location of Israel as well as all the sustainability benefits that photovoltaics can offer to the country. However, an appropriate policy framework is needed for the support of this technology and the exploitation of the high export potential. The technology CMM for generator is assigned as high priority as it seems to have a great potential in Israel. On the other hand, geothermal energy and oil steam improvement are not recommended options for this case. Geothermal energy has very large potential in Israel, but it does not suit to the country. In addition, limited are the opportunities that oil steam improvement could offer because Israel has already decided to reduce dramatically the share of oil in its electricity generation.

Kenya: Electricity is expensive for the majority of the households and only $46 \%$ of urban and $3.8 \%$ of rural households have access to electricity. Nationally, this translates to only $15 \%$ households with access to electricity. Kenya has no proven reserves of coal, methane, natural gas or oil ${ }^{[29]}$. The only important resources are mainly hydro (dams), mini/micro hydro (rivers) and geothermal, which are categorized as high and low priority alternatives respectively. Hydroelectricity plants provide about $75 \%$ of all electrical output. Large are the hydro (dams) potentials in Kenya. There are several rivers that could produce large amounts of energy. The technologies biomass boiler and biogas for generator are considered as high priority choices. Heavy is the dominance of biomass energy in the household sector (close to $92 \%$ of households) and there is a high affinity with the strategic/developmental planning of the country. Furthermore, plenty are considered the sustainability benefits from the application of technology biogas for generator in Kenya, with the most important the contribution to the country's economic development. The country depends its electricity generation almost exclusively in hydro energy. Therefore, technologies such as coal to gas, oil steam improvement and coal steam improvement are not considered applicable or relevant for the case of Kenya.
Thailand: Electricity generation in Thailand comes mainly from conventional thermal units, which use primarily natural gas and secondary coal and oil. Hydro energy is also used for electricity generation. The country imports a great amount of natural gas in order to fulfil its energy needs ${ }^{[29]}$. The alternative steam boiler upgrading resulted as a high priority technology for Thailand as several are the environmental benefits gained from its implementation, such as the achievement of local clean air as well as the domestic resources conservation. High priority technology options turned out to be biogas for generator and biomass boiler due to the fact that they are able to contribute to the decrease of the country's dependency on imported fuel and assist the economic growth. In addition, surprisingly high affinity with the country's strategic-developmental planning has the technology biogas for generator in Thailand. The country has great potential of biogas and the installed biogas systems generate approximately $20 \mathrm{MW}$ of power, with an estimated total generating potential of $278 \mathrm{MW}^{[29]}$. There is a huge potential of biomass in Thailand and most CDM projects in pipeline also fall under the same category. On the contrary, the technology hydro (dams) appears not to be applicable for this case. There is a high potential for solar (pv) considering the resource availability. However, the technology is low ranked, an outcome which can be explained considering the very high investment cost and the less output that leads to very low efficiency.

The outcomes obtained were presented in the CleanAir 2007-the Ninth International Conference on Energy for a Clean Environment ${ }^{[30]}$ and were judged as realistic and consistent by the relevant stakeholders, which participated. In addition to this, the presented approach was appraised as a collective and interactive policy framework, providing the flexibility to assess the contribution of technology options to the sustainable development needs and priorities of the examined countries.

Based on the workshops insights it can be generally noted that the adopted approach:

- Does not intent to replace the decision maker, it was proved to be a useful decision support approach by structuring the decision process and assisting the decision makers to pre-assess the most suitable sustainable energy technologies to transfer and implement in a particular developing country through the CDM

- Is relatively straightforward in order to incorporate direct experts' preferences in a transparent and adequate way 
- Is country specific, since the weights and the performances depend on the country's specific energy characteristics, as well as its different circumstances, development needs and perspectives

The outcome of the proposed approach seem to be realistic, since the technologies that are matured and fully commercialized, with proven sustainability benefits are high scored in most of the case study countries. In particular:

- Biomass boiler is a high priority for all the countries apart from China, due to its sustainable characteristics and related potential to be applied

- Wind energy is a high priority to all countries, especially for their isolated areas, since wind technology can be considered as full commercialized and matured enough

- For all case study countries oil is not considered as a high priority alternative for electricity generation. They tend to become independent from oil, as far as electricity generation is concerned, due to the high costs and uncertainties related with oil

- Coal to gas is a high priority only for Israel that obtains great offshore natural gas reserves, has established a strategic communication to allow the import of Egyptian natural gas and tends to rely more on intern sources. On the contrary, this technology does not seem appealing for the rest of the countries due to the high import costs of natural gas

- CMM for generator is a technology alternative with great economic impact, environmental and social benefits, but can only be applied in countries with significant coal reserves. As a result only in China and Israel this technology is applicable. For the rest of the countries this technology is not recommended

It should be clearly also stated that:

Indeed, the selection of the technology implemented under the CDM has to be turned towards the host country specific needs and priorities and related decision support approaches and methods can have a significant contribution in this respect. A perspective for further research is to incorporate implementation chains' aspects (e.g., legislation, culture, financing resources, training, bureaucratic procedures) in the presented approach for a number of technologies and to recommend how this could be improved through the CDM.

\section{ACKNOWLEDGEMENTS}

This study is based on research conducted within the ENTTRANS: The potential of transferring and implementing sustainable energy technologies through the Clean Development Mechanism of the Kyoto Protocol FP6 project, funded by the European Commission (EC-DG Research FP6). The authors would like to acknowledge that they are grateful to the project partners in Chile (Cambio Climático y Desarollo-CC and D), China (Kunming University of Science and Technology-Faculty of Environmental Science and Engineering-KUST), Israel (The Interdisciplinary Centre for Technological Analysis and Forecasting at Tel Aviv University-ICTAF), Kenya (Intermediate Technology Development Group East Africa-ITDG-EA) and Thailand (Asian Institute of Technology-AIT), whose helpful remarks and fruitful observations were invaluable for the development of this research. The content of the study is the sole responsibility of its authors and does not necessary reflect the views of the EC.

\section{REFERENCES}

1. UNFCCC, 2001a. FCCC/CP/2001/13/Add.1, Decision 4/CP.7, Annex, Seventh Conference of the Parties to the UNFCCC, November 2001, Marrakech, Morocco.

2. International Emission Trading Association, IETA, 2006. Greenhouse Gas market 2006, Financing Response to Climate Change: Moving to Action.

3. UNEP Risoe Centre, 2007. CDM Pipeline Overview, <http://www.cd4cdm.org $>$.

4. Flamos, A., H. Doukas, K. Patlitzianas and J. Psarras, 2005. CDM-PAT: A decision support tool for the pre-assessment of CDM projects. Int. J. Comput. Appl. Technol. (IJCAT), Vol. 22, Nos. 2/3.

5. Buchholz, T.S., T.A. Volk and V.A. Luzadis, 2008. A participatory systems approach to modeling social, economic and ecological components of bioenergy. Energy Policy, In Press.

6. Georgopoulou, E., Y. Sarafidis and D. Diakoulaki, 1998. Design and implementation of a Group DSS for sustaining renewable energies exploitation. Eur. J. Operat. Res., 109 (2): 483-500.

7. Konidari, P. and D. Mavrakis, 2008. A multicriteria evaluation method for climate change mitigation policy instruments. Energy Policy, In Press. 
8. Mirasgedis, S. and D. Diakoulaki, 1997. Multiple criteria analysis vs. externalities assessment for the comparative evaluation of eletcricity generation systems. Eur. J. Operat. Res., 102 (2): 364-379.

9. Diakoulaki, D., P. Georgiou, C. Tourkolias, E. Georgopoulou, D. Lalas, S. Mirasgedis and Y. Sarafidis, 2007. A multicriteria approach to identify investment opportunities for the exploitation of the clean development mechanism. Energy Policy, 35 (2): 1088-1099.

10. Doukas, H., A. Botsikas and J. Psarras, 2007. Multi Criteria Decision Aid for the Formulation of Sustainable Technological Energy Priorities using Linguistic Variables. Eur. J. Operat. Res., 182 (2): 844-855.

11. Cherni, J.A., I. Dyner, F. Henao, P. Jaramillo, R. Smith and R.O. Font, 2007. Energy supply for sustainable rural livelihoods. A multi-criteria decision-support system. Energy Policy, 35 (3): 1493-1504.

12. Geldermann, J., T. Spengler and O. Rentz, 2000. Fuzzy outranking for environmental assessment. Case study: iron and steel making industry. Fuzzy Sets and Systems, 115 (1): 45-65.

13. Al-Rashdan, D., B. Al-Kloub, A. Dean and T. Al-Shemmeri, 1999. Environmental impact assessment and ranking the environmental projects in Jordan. Eur. J. Operat. Res., 118 (1): 30-45.

14. Beccali, M., M. Cellura and M. Mistretta, 2003. Decision-making in energy planning. Application of the ELECTRE method at regional level for the diffusion of renewable energy technology. Renewable Energy, 28 (13): 2063-2087.

15. Doukas, H., K.D. Patlitzianas and J. Psarras, 2006. Supporting the Sustainable Electricity Technologies in Greece Using MCDM. Resources Policy, 31 (2): 129-136.

16. Greening, L.A. and S. Bernow, 2004. Design of coordinated energy and environmental policies: Use of multi-criteria decision-making. Energy Policy, 32 (6): 721-735.

17. Jacquet-Lagreze, E. and Y. Siskos, 2001. Preference disaggregation: 20 years of MCDA experience. Eur. J. Operat. Res., 130 (2) : 233-245.

18. Dinca, C., A. Badea, P. Rousseaux and T. Apostol, 2007. A multi-criteria approach to evaluate the natural gas energy systems. Energy Policy, 35 (11): 5754-5765.

19. Pohekar, S.D. and M. Ramachandran, 2004. Application of multi-criteria decision making to sustainable energy planning-A review. Renewable and Sustainable Energy Rev., 8 (4): 365-381.
20. Arondel, C. and P. Girardin, 1998. Sorting cropping systems on the basis of their impact on groundwater quality. Cahiers du LAMSADE No. 158, Universite Paris-Dauphine.

21. Diakoulaki, D., Y. Kormentza and V. Hontou, 2000. An MCDA approach to burden-sharing among industrial branches for combating climate change. Paper Presented at the 51st Meeting of the European Working Group on MCDA, Madrid, 30-31.

22. Montano-Guzman, L., 2000. Une méthodologie d'aide multicritère a la décision pour la diagnostique de l'entreprise. Paper Presented at the 51 st Meeting of the European Working Group on MCDA, Madrid, 30-31 March 2000.

23. Zopounidis, C. and A.I. Dimitras, 1998. Multicriteria Decision Aid Methods for the Prediction of Business Failure. Kluwer Academic Publishers, Dordrecht, The Netherlands.

24. Georgopoulou, E., Y. Sararidis, S. Mirasgedis, S. Zaimi and D.P. Lalas, 2003. A multiple criteria decision-aid approach in defining national priorities for greenhouse gases emissions reduction in the energy sector. Eur. J. Operat. Res., 146 (1): 199-215.

25. Mousseau, V. and R. Slowinski, 1998. Inferring an ELECTRE TRI model from assignment examples. J. Global Optimiz., 12: 157-174.

26. Yu, W., 1992. ELECTRE TRI: Aspects méthodologiques et manuel d'utilisation, Université Paris-Dauphine, Document du LAMSADE No. 74.

27. Maystre, L.Y., J. Pictet and J. Simos, 1994. Méthodes multicritères ELECTRE: Description, conseils pratiques et cas d'application à la gestion de l'environnement. Presse Polytechniques et Universitaires Romandes, Ecole Polytechnique Fédérale de Lausanne (EPFL), CH-1015 Lausanne, Suisse.

28. Mousseau, V., R. Slowinski and P. Zielniewicz, 1999. ELECTRE TRI 2.0a-Methodological guide and user's manual, Documents du LAMSADE No 111, University Paris-Dauphine.

29. Foundation Joint Implementation Network (JIN), 2007. ENTTRANS: The potential of transferring and implementing sustainable energy technologies through the Clean Development Mechanism of the Kyoto Protocol FP6 project, European Commission Final Activity Report.

30. Flamos, A., H. Doukas, C. Karakosta and J. Psarras, 2007. MCDM Approach for Assessing CDM Energy Technologies Towards Sustainable Development. Ninth International Conference on Energy for a Clean Environment, CleanAir 2007, Povoa de Varzim, Portugal. 